\title{
Double variants in TSHR and DUOX2 in a patient with hypothyroidism: case report
}

\author{
Sasivari, Zerin ; Szinnai, Gabor ; Seebauer, Britta ; Konrad, Daniel ; Lang-Muritano, Mariarosaria
}

\begin{abstract}
Thyroid dyshormonogenesis (TDH) is characterized by the defective synthesis of thyroid hormones. We present a patient with congenital hypothyroidism $(\mathrm{CH})$ who presented in newborn screening with elevated serum thyroid-stimulating hormone $(\mathrm{TSH})$, decreased free thyroxine $(\mathrm{fT}<$ jats:sub $>4</$ jats:sub $>$ ) and increased thyroglobulin $(\mathrm{Tg})$ concentrations. Ultrasound scan revealed a properly structured thyroid gland. Treatment with L-thyroxine was initiated. At the age of 2 years, thyroxine replacement was stopped. The patient remained untreated until 6 years of age when TSH levels progressively increased and L-thyroxine treatment was restarted at a dose of $12.5 \mathrm{~g} /$ day. Genetic analysis revealed a double heterozygosity for likely pathogenic variants of dual oxidase $2(<$ jats:italic $>$ DUOX $2</$ jats:italic $>)$ and thyroid stimulating hormone receptor $<$ jats:italic $>(\mathrm{TSHR}</$ jats:italic $>)$. Both genes were earlier shown to be associated with $\mathrm{CH}$. In a literature review, our patient was compared to previously published patients with similar clinical characteristics, and a good genotype-phenotype correlation was identified.
\end{abstract}

DOI: https://doi.org/10.1515/jpem-2019-0051

Posted at the Zurich Open Repository and Archive, University of Zurich

ZORA URL: https://doi.org/10.5167/uzh-178432

Journal Article

Published Version

Originally published at:

Sasivari, Zerin; Szinnai, Gabor; Seebauer, Britta; Konrad, Daniel; Lang-Muritano, Mariarosaria (2019). Double variants in TSHR and DUOX2 in a patient with hypothyroidism: case report. Journal of Pediatric Endocrinology Metabolism, 32(11):1299-1303.

DOI: https://doi.org/10.1515/jpem-2019-0051 


\section{Case Report}

Zerin Sasivari, Gabor Szinnai, Britta Seebauer, Daniel Konrad and Mariarosaria Lang-Muritano*

\section{Double variants in $T S H R$ and DUOX2 in a patient with hypothyroidism: case report}

https://doi.org/10.1515/jpem-2019-0051

Received February 27, 2019; accepted August 12, 2019; previously published online September 21, 2019

\begin{abstract}
Thyroid dyshormonogenesis (TDH) is characterized by the defective synthesis of thyroid hormones. We present a patient with congenital hypothyroidism (CH) who presented in newborn screening with elevated serum thyroid-stimulating hormone (TSH), decreased free thyroxine ( $\mathrm{fT}_{4}$ ) and increased thyroglobulin ( $\mathrm{Tg}$ ) concentrations. Ultrasound scan revealed a properly structured thyroid gland. Treatment with L-thyroxine was initiated. At the age of 2 years, thyroxine replacement was stopped. The patient remained untreated until 6 years of age when TSH levels progressively increased and L-thyroxine treatment was restarted at a dose of $12.5 \mu \mathrm{g} /$ day. Genetic analysis revealed a double heterozygosity for likely pathogenic variants of dual oxidase 2 (DUOX2) and thyroid stimulating hormone receptor (TSHR). Both genes were earlier shown to be associated with $\mathrm{CH}$. In a literature review, our patient was compared to previously published patients with similar clinical characteristics, and a good genotype-phenotype correlation was identified.
\end{abstract}

Keywords: congenital hypothyroidism; DUOX2 variant; TSHR variant.

\footnotetext{
*Corresponding author: Mariarosaria Lang-Muritano, MD, Department of Paediatric Endocrinology and Diabetology, University Children's Hospital, Steinwiesstrasse 75, CH-8032 Zurich, Switzerland; and Children's Research Centre, University Children's Hospital, Zurich, Switzerland, Phone: +41 4426672 73, E-mail: mariarosaria.lang@kispi.uzh.ch

Zerin Sasivari: Department of Paediatric Endocrinology and Diabetology, University Children's Hospital, Zurich, Switzerland Gabor Szinnai: Department of Paediatric Endocrinology and Diabetology, University Children's Hospital, Basel, Switzerland Britta Seebauer: Department of Medical Genetics, University Hospital Basel, University of Basel, Basel, Switzerland Daniel Konrad: Department of Paediatric Endocrinology and Diabetology, University Children's Hospital, Zurich, Switzerland; and Children's Research Centre, University Children's Hospital, Zurich, Switzerland
}

\section{Introduction}

Congenital hypothyroidism $(\mathrm{CH})$ occurs with an incidence of 1:3000-1:4000 [1]. Neonatal screening for $\mathrm{CH}$ was introduced in Switzerland in 1977 to prevent mental retardation in affected newborns [2]. Newborn screening in Switzerland determines thyroid-stimulating hormone (TSH) but not thyroxine $\left(\mathrm{T}_{4}\right)$ concentration. Thus, newborns with central or secondary hypothyroidism are missed in Switzerland.

Primary $\mathrm{CH}$ can be classified into two forms: thyroid dysgenesis, which accounts for approximately $80-85 \%$ of all cases with permanent primary $\mathrm{CH}$ including resistance to TSH, and thyroid dyshormonogenesis (TDH), accounting for $10-15 \%$ of cases. Thyroid dysgenesis is caused by disordered development of the thyroid gland and results in athyreosis, hypoplastic or ectopic thyroid gland. TSH resistance can cause hypoplastic or normally sized thyroid gland. TDH is characterized by eutopic thyroid gland of normal size, or goiter [1].

Most forms of TDH are transmitted autosomal recessively and so far variants in seven different genes coding for the following proteins have been identified: thyroid peroxidase (TPO), thyroglobulin $(T G)$, pendrin (causing Pendred syndrome [SLC26A4/PDS]), sodium iodide transporter (SLC5A5/NIS), dual oxidase 2 (DUOX2), dual oxidase maturation factor (DUOXA2) and iodotyrosine deiodinase (IYD) [3].

DUOX2 is a transmembrane protein. It generates $\mathrm{H}_{2} \mathrm{O}_{2}$, which is required for the synthesis of thyroid hormones. Variants in the DUOX2 gene may result in transient or permanent dyshormonogenesis [3].

The TSH receptor (TSHR) gene codes for the TSHreceptor, which is a transmembrane protein binding TSH and consequently stimulating thyroid hormone production. Its variant causes TSH resistance resulting in increased TSH levels in an effort to maintain normal thyroid hormone secretion, which is not always achievable. TSHR pathogenic variants cause variable phenotypes, ranging from asymptomatic to severe hyper or hypothyroidism. Carriers of inactivating biallelic TSHR gene 
variants are likely to be identified by neonatal screening, whereas those with autosomal dominant-inherited monoallelic variants appear in milder forms and may be missed in the screening $[4,5]$.

Herein, we present a boy with mild $\mathrm{CH}$ due to double variants in the TSHR and DUOX2 gene.

\section{Case report}

The patient was born of non-consanguineous parents at term, his body weight was $3370 \mathrm{~g}$ (P50), and his birth length was $50 \mathrm{~cm}$ (P50). Pregnancy and spontaneous vaginal delivery were uneventful. In the newborn screening on the 10th postnatal day, serum TSH concentration was elevated (79.1 mU/L [normal range: 0.1-10.5]). In the recall test after a few days, the TSH level was $222 \mathrm{mU} / \mathrm{L}$ and free thyroxine $\left(\mathrm{fT}_{4}\right)$ was decreased $(0.27 \mathrm{ng} / \mathrm{dL}$ [0.8-2.31]). Thyroglobulin (Tg) was massively increased $(980 \mu \mathrm{g} / \mathrm{mL}$ $[<75 \mu \mathrm{g} / \mathrm{mL}])$. At this point, treatment with L-thyroxine was started with a dose of $25 \mu \mathrm{g} /$ day. Five days later, the dose was increased to $50 \mu \mathrm{g} /$ day. Further evaluation revealed thyroid peroxidase, Tg and TSH receptor antibodies within the normal range. Ultrasound was performed during a follow-up visit 4 weeks after birth, showing a homogenous thyroid gland loco classico with a longitudinal dimension of $15 \mathrm{~mm}$ and each lobe having a width of $7 \mathrm{~mm}$. Family history was unremarkable for thyroid problems except for the maternal grandmother, who developed hypothyroidism after menopause. All these findings suggested a likely diagnosis of TDH. A perchlorate test to distinguish from a thyroid dysgenesis was not performed.

At the age of 2 years, the patient's thyroid function was reevaluated after cessation of L-thyroxine $(50 \mu \mathrm{g})$ substitution 4 weeks earlier. Scintigraphy with $4 \mathrm{MBq}$ 123Jcd revealed homogenous accumulation of the radionuclide in a correctly located thyroid gland.

After discontinuation of thyroid hormone replacement, TSH concentration increased and remained slightly elevated (Figure 1), whereas $\mathrm{fT}_{4}$ was always within normal limits. At this time, the patient showed no symptoms. Therefore, therapy was not restarted as subclinical hypothyroidism should not be treated unless there are signs or symptoms of hypothyroidism [6].

The patient remained untreated until the age of 6 years when complaints of fatigue and dry skin appeared. At presentation, the patient was clinically examined and showed no signs of infection, so no blood test for infection parameters was done. As a differential diagnosis for fatigue, serology tests for celiac disease were done with negative results.

As TSH levels were also increasing, L-thyroxine replacement was restarted with a dose of $12.5 \mu \mathrm{g} /$ day. At the time of treatment reinstitution, the patient's height was $119.4 \mathrm{~cm}$ ( $\mathrm{P}$ 50, +0.05 standard deviation [SD]), weight was $24.5 \mathrm{~kg}(\mathrm{P} 75,+0.84 \mathrm{SD})$ and body mass index (BMI) was $17.2 \mathrm{~kg} / \mathrm{m}^{2}$ (P 75-90; z-score $+1.2 \mathrm{SD}$ ). Thus, the patient was not overweight.

During follow-up, TSH levels remained stable within the normal range, fatigue disappeared and L-thyroxine therapy was continued with a dose of $25 \mu \mathrm{g}$ /day until adulthood when the patient was transitioned to adult endocrinology.

\section{Materials and methods}

To analyze the patient's DNA, a custom-designed Illumina sequencing panel containing genes involved in thyroid dysgenesis (FOXE1,

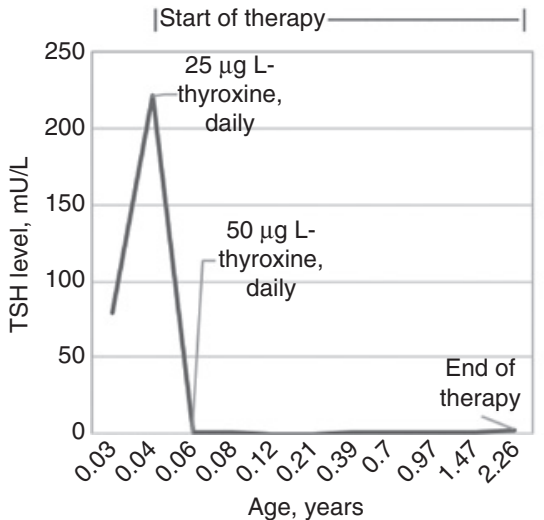

Figure 1: Course of TSH concentration over time.

The dose per kilogram of L-thyroxine on the first episode of therapy ranged from $3 \mu \mathrm{g} / \mathrm{kg}$ to $10 \mu \mathrm{g} / \mathrm{kg}$. At restart of therapy, the dose was approximately $0.3-0.5 \mu \mathrm{g} / \mathrm{kg} /$ day. Current dose is $0.37 \mu \mathrm{g} / \mathrm{kg} / \mathrm{day}$. 
NKX2-1, NKX2-5, PAX8 and TSHR) and dyshormonogenesis (DUOX2, DUOXA2, IYD, SLC5A5/NIS, SLC26A4/PDS, TG and TPO) was used. Library preparation was performed according to the standard protocol (Nextera rapid capture custom enrichment kit, Illumina, San Diego, CA, USA), followed by sequencing on the MiSeq sequencing platform (Illumina, San Diego, CA, USA). Sequencing data were analyzed using the software Variant Studio (Illumina, San Diego, CA, USA) and SequencePilot (JSI medical systems, Ettenheim, Germany). Variants of interest were confirmed by Sanger sequencing.

\section{Ethical statement}

Informed consent was obtained from all individuals included in this study. The research related to human use complied with all the relevant national regulations and institutional policies, and was in accordance with the tenets of the Helsinki Declaration, and has been approved by the authors' Institutional Review Board or equivalent committee.

\section{Results}

The patient is heterozygous for two variants in the genes DUOX2 and TSHR with a known phenotype of TDH. In DUOX2, the sequence variant c.602dupG was identified. One base pair is duplicated with the molecular consequence of a frameshift (p.[Gln202ThrfsTer99]). In the ClinVar database, it is described as pathogenic/likely pathogenic for dyshormonogenesis [7, 8].

In the exon 1 of the TSHR gene, the sequence variant c.122 $\mathrm{G}>\mathrm{C}$ has been identified. A guanine replaces cysteine which results in an amino acid exchange from cysteine to serine (p.[Cys41Ser]). This variant is asserted to be pathogenic for $\mathrm{CH}$ [9].

In both the genes, there was no evidence of a second pathogenic sequence variant. No gene dose analysis was implemented. The patient is a heterozygous carrier of the DUOX2 sequence variant associated with mild hypothyroidism and the TSHR sequence variant associated with a TSH resistance.

\section{Discussion}

According to the consensus guidelines of the European Society for Paediatric Endocrinology, transient hypothyroidism is defined as elevated TSH levels in the first days of a newborn with normalized values after a period of no treatment [10]. After the off-treatment period, the patient had increased TSH values slightly over the range which would fit the definition of transient hypothyroidism. Yet our patient needed a restart of therapy, and the symptoms of fatigue disappeared after retreatment. Therefore, it is difficult to definitively settle whether our patient had transient hypothyroidism.

$\mathrm{CH}$ has recently been shown to occur not only as monogenic but also as an oligogenic disease, especially in patients with eutopic thyroid gland [11]. Our patient carries two gene variants, one in the TSHR gene and one in the DUOX2 gene, both being previously associated with $\mathrm{CH}$. If only one of these genes is mutated, reported phenotypes are variable and also depend on whether both or one allele is affected. If only one allele is mutated, symptoms are usually mild and hypothyroidism may be transient or mild. Such an observation has been made for both, DUOX2 variants [12] and TSHR variants [5, 13]. However, correlation between genotypes and phenotypes may be more complex as biallelic DUOX2 variants also presented with only moderate clinical signs of hypothyroidism.

In the literature, 10 cases with double heterozygous variants of the TSHR and DUOX2 genes similar to our patient have been reported with available clinical data and are reviewed in Table 1 [4, 13-15]. Additional cases with double mutations have been published but are not included in the table as clinical data were not available [16-19].

The presence of an additional monoallelic DUOX2 variant in a newborn with a monoallelic TSHR variant makes a positive result in the newborn TSH screening 10 times more probable compared to carriers with a TSHR variant alone. Along this line, the frequency of double heterozygosity in patients with $\mathrm{CH}$ was reported to be much higher than in the general population in Japan [4]. Accordingly, only three out of 11 patients presented in Table 1 revealed no or only slightly elevated TSH values in the confirmative blood sample after newborn screening (upper cutoff value of $10.5 \mathrm{mU} / \mathrm{L}$ ). All other cases showed strongly elevated TSH values and very low $\mathrm{fT}_{4}$ levels, resulting in immediate L-thyroxine replacement. Only four of the latter patients had to continue thyroxine therapy after re-evaluation, whereas the other four showed stable TSH levels in the upper range, similar to our patient. Thus, the genotype alone does not seem to predict the clinical follow-up and the need for replacement therapy.

Thyroid size was reduced in the majority of reviewed patients fitting more to TSHR sequence variants than to DUOX2 variants. Unfortunately, TG concentration was reported in only one of the reviewed patients. Like in our patient, it was increased. It would be interesting to know whether Tg concentration was also elevated in the other patients.

Watching the variations, it seems that p.R450H in TSHR is a frequent variant in combination with a DUOX2 


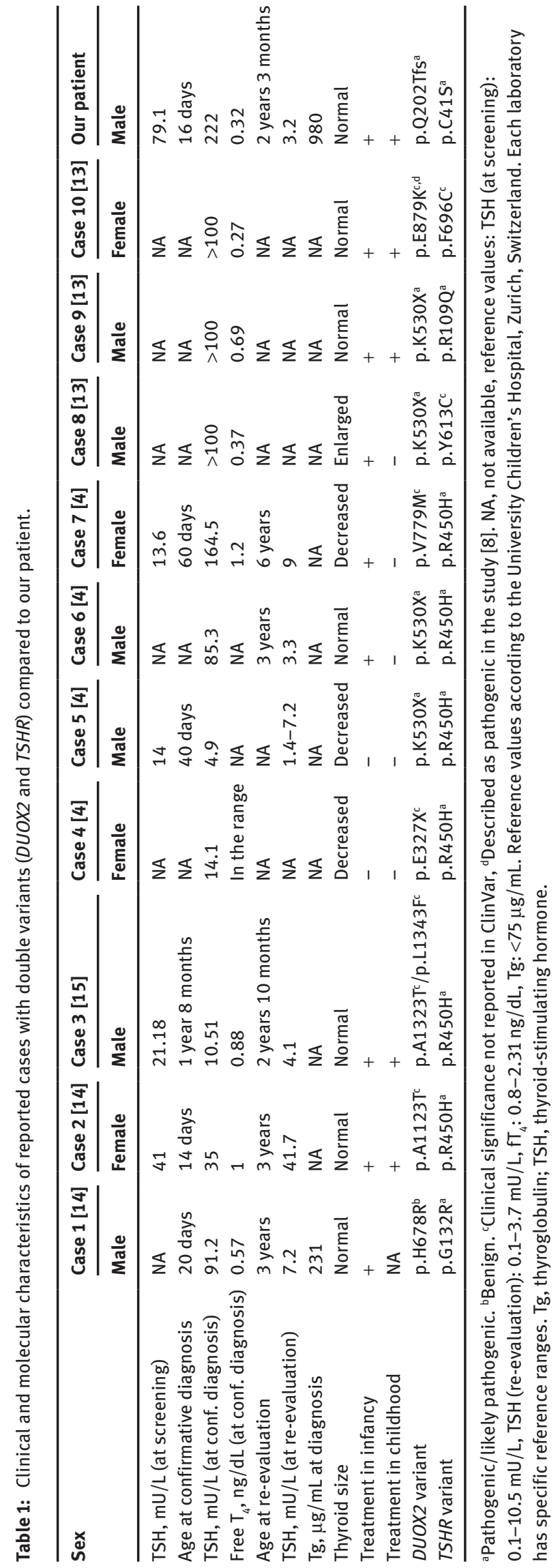

variant. But this TSHR allele variant has also been demonstrated to be a common variant in the Japanese and Taiwanese population, independent of an additional pathogenic variant [13].

In conclusion, our data demonstrate higher probability for $\mathrm{CH}$ in patients with double heterozygosity for TSHR and DUOX2. However, the necessity of continuous thyroid replacement is difficult to predict despite good genotypephenotype correlation.

\section{Established facts and learning points}

Established facts

- Carriers of inactivating biallelic TSHR gene variants are likely to be identified by neonatal screening, whereas those with monoallelic variants may be missed in the screening $[4,5]$.

- DUOX2 pathogenic variants can cause transient or permanent hypothyroidism [12].

- The coexistence of DUOX2 and TSHR variants leads to a higher probability of $\mathrm{CH}$ [4].

\section{Learning points}

- We report the first case with this combination of pathogenic variants of DUOX2 and TSHR with long-term clinical follow-up.

- Patients with variants of TSHR and DUOX2 show differences in phenotype despite the same genotype.

Author contributions: Sasivari Z analyzed the patient's dossier and wrote the paper. Seebauer B is responsible for genetic investigation. Szinnai G, Konrad D and Seebauer B provided critical feedback and helped shape the manuscript. Lang-Muritano M treated the patient from birth and was the supervisor of this paper.

Research funding: None declared.

Employment or leadership: None declared.

Honorarium: None declared.

Competing interest: The authors declare that they have no conflict of interest.

\section{References}

1. Rastogi MV, LaFranchi SH. Congenital hypothyroidism. Orphanet J Rare Dis 2010;5:17.

2. Illig R, Largo RH, Qin Q, Torresani T, Rochiccioli P, et al. Mental development in congenital hypothyroidism after neonatal screening. Arch Dis Child 1987;62:1050-5. 
3. Szinnai G. Clinical genetics of congenital hypothyroidism. Endocr Dev 2014;26:60-78.

4. Abe K, Narumi S, Suwanai AS, Adachi M, Muroya K, et al. Association between monoallelic. Eur J Endocrinol 2018;178:137-44.

5. Persani L, Calebiro D, Cordella D, Weber G, Gelmini G, et al. Genetics and phenomics of hypothyroidism due to TSH resistance. Mol Cell Endocrinol 2010;322:72-82.

6. Salerno M, Capalbo D, Cerbone M, De Luca F. Subclinical hypothyroidism in childhood - current knowledge and open issues. Nat Rev Endocrinol 2016;12:734-46.

7. Pfarr N, Korsch E, Kaspers S, Herbst A, Stach A, et al. Congenital hypothyroidism caused by new mutations in the thyroid oxidase 2 (THOX2) gene. Clin Endocrinol (Oxf) 2006;65:810-5.

8. Muzza M, Rabbiosi S, Vigone MC, Zamproni I, Cirello V, et al. The clinical and molecular characterization of patients with dyshormonogenic congenital hypothyroidism reveals specific diagnostic clues for DUOX2 defects. J Clin Endocrinol Metab 2014;99:E544-53.

9. Alberti L, Proverbio MC, Costagliola S, Romoli R, Boldrighini $B$, et al. Germline mutations of TSH receptor gene as cause of nonautoimmune subclinical hypothyroidism. J Clin Endocrinol Metab 2002;87:2549-55.

10. Léger J, Olivieri A, Donaldson M, Torresani T, Krude H, et al. European Society for Paediatric Endocrinology consensus guidelines on screening, diagnosis, and management of congenital hypothyroidism. Horm Res Paediatr 2014;81:80-103.

11. Nicholas AK, Serra EG, Cangul H, Alyaarubi S, Ullah I, et al. Comprehensive screening of eight known causative genes in congenital hypothyroidism with gland-in-situ. J Clin Endocrinol Metab 2016;101:4521-31.
12. Fu C, Luo S, Zhang S, Wang J, Zheng H, et al. Next-generation sequencing analysis of DUOX2 in 192 Chinese subclinical congenital hypothyroidism (SCH) and $\mathrm{CH}$ patients. Clin Chim Acta 2016;458:30-4.

13. Fu C, Wang J, Luo S, Yang Q, Li Q, et al. Next-generation sequencing analysis of TSHR in 384 Chinese subclinical congenital hypothyroidism $(\mathrm{CH})$ and $\mathrm{CH}$ patients. Clin Chim Acta 2016;462:127-32.

14. Jin HY, Heo SH, Kim YM, Kim GH, Choi JH, et al. High frequency of DUOX2 mutations in transient or permanent congenital hypothyroidism with eutopic thyroid glands. Horm Res Paediatr 2014;82:252-60.

15. Satoh M, Aso K, Ogikubo S, Yoshizawa-Ogasawara A, Saji T. Hypothyroidism caused by the combination of two heterozygous mutations: one in the TSH receptor gene the other in the DUOX2 gene. J Pediatr Endocrinol Metab 2015;28:657-61.

16. de Filippis T, Gelmini G, Paraboschi E, Vigone MC, Di Frenna M, et al. A frequent oligogenic involvement in congenital hypothyroidism. Hum Mol Genet 2017;26:2507-14.

17. Park KJ, Park HK, Kim YJ, Lee KR, Park JH, et al. DUOX2 mutations are frequently associated with congenital hypothyroidism in the Korean population. Ann Lab Med 2016;36:145-53.

18. Sun F, Zhang JX, Yang CY, Gao GQ, Zhu WB, et al. The genetic characteristics of congenital hypothyroidism in China by comprehensive screening of 21 candidate genes. Eur J Endocrinol 2018;178:623-33.

19. Fan X, Fu C, Shen Y, Li C, Luo S, et al. Next-generation sequencing analysis of twelve known causative genes in congenital hypothyroidism. Clin Chim Acta 2017;468:76-80. 